\title{
The determinants of stakeholder engagement in digital platforms
}

Giampaolo Vigliaa, $\square$, Rebecca Perab, Enrique Bignéc

a University of Portsmouth, Department of Marketing and Sales, Richmond Building Portland Street, PO13DE Portsmouth, UK

b University of Eastern Piedmont, Department of Economics and Business, via Perrone 18, 28100 Novara, Italy

c University of Valencia, Faculty of Economics, Avda. Tarongers s/n, 46022 Valencia, Spain

\begin{abstract}
Consumer engagement has been heralded as strategic in facilitating sales growth, competitive advantage, and profitability. Expanding the notion of consumer engagement to the stakeholder context, this study examines the determinants of multistakeholder digital engagement. Based on a digital setting (Expo2015), this study collected all the social media posts $(n=984)$ in the Facebook page with restricted access to the stakeholders involved in the event. Initial regression results suggest that the presence of transformation, in terms of activation of creative resource integration in posts, is a strong predictor of compliant and interactive engagement. Fuzzy-set qualitative comparative analysis (fsQCA) shows the configurations of cognitive and emotional attributes leading to compliance and interaction. Stakeholder engagement is an interactive experiential process based on actors' engagement with a focal organization, but more intensively with other stakeholder community members.
\end{abstract}

Keywords: stakeholders; engagement; social media; fsQCA, compliance, interaction

\section{Introduction}

Despite the growing importance of stakeholder integration in practice, academic discussion of stakeholder inclusion remains in its infancy (Driessen et al., 2013), especially regarding the role played by social media. Following Hillebrand (2015), the marketing discipline should expand its rather restrictive focus on customers toward a view of marketing that acknowledges the interrelatedness of stakeholders. Stakeholder relationships constitute a source of competitive advantage (Surroca et al. 2010) that generate financial benefits, protect the firm against hostility (such as product harm crises), favors corporate social responsibility (Barrena, López and Romero, 2016) and contribute to firm survival (Choi and Wang 2009). More specifically, strong and positive stakeholder relationships reflect the willingness of stakeholders to support the firm with their resources (Maignan and Ferrell 2004).

Stakeholder engagement has recently risen on the agenda of marketing studies mostly due to the introduction of digital media. The relevance of engagement is illustrated by the inclusion in the Marketing Science Institute's 2014-2016 and 2016-2018 Research Priorities (MSI 2014, 2016), and by the growing interest on the topic from academics and practitioners. Within a multi-stakeholder ecosystem paradigm fostering stakeholders' content generation in social media is not a simple task. Organizational messages in fact often bounce randomly around in the online environment (Hennig-Thuray et al. 2010; Hennig-Thuray et al. 2013), being comparable to a pinball match. Engagement cannot be forced. It can be facilitated by a tertius iungens (or "third who joins") (Obstfeld, 2005) platform that provides extra value and contributes to the analyses of issues that are relevant to stakeholders.

Addressing the calls for research (e.g., Brodie et al. 2013) on dyadic and/or networked aspects of engagement beyond consumers, this analysis intends to explore the 
determinants of engagement within a broader intra and extra-organization focus. As such, this research explores an ecosystem that, indeed, embraces a much wider sociocultural system than pure traditional stakeholder relationships such as employee/organization or supplier/organization. The rationale underlying such an approach is that engagement captures relationships among many different groups. Gyrd-Jones and Kornum (2013) defined this new broader perspective as a "stakeholder ecosystem", which encapsulates both the network nature of these relationships and the complex set of subcultures that make up this ecosystem.

Expo2015's Facebook closed group, with restricted access to 248 stakeholders involved in the event (e.g., governments, civil society, chambers of commerce, universities, companies), represents an appropriate avenue to explore the determinants of engagement in the digital realm. Expo2015 is a Universal Exposition, a global event that is held every five years and has attracted over 20 million of visitors.

The aim of the paper is unpacking the determinants of online stakeholder engagement, showing the peculiarities with respect to consumer engagement. In addition, the study investigates how the focal organization, i.e., the offline or online platform that connects stakeholders, can help to maximise stakeholder engagement.

The next section presents the theory, discussing the constituents and the actors of online stakeholder engagement. The section ends with a visual conceptual model. The empirical Expo2015 case, assessed through regression and QCA, validates the theory. After presenting the findings, the paper concludes with the theoretical and practical implications and clarifies the role of the focal organization in enacting stakeholder engagement.

\section{Theory}

Stemming from Schmitt (2012), psychological engagement can be seen as functional or social. The first is object-centered and functionally driven while the second derives from an interpersonal and socio-cultural perspective and it is typical of consumer relationships (Martí et al., 2014). Considering the paucity of studies on stakeholder engagement, an analysis of the current debate from a consumer perspective is essential to define a working definition of Stakeholder Engagement. Dijkmans et al. (2015) define engagement in terms of a combination of cognition (e.g., being interested in a company's activities), emotions (feeling positive about a company's activities) and behaviors (participation in the company's activities). Mollen and Wilson (2010) suggest that a consumer's engagement extends beyond mere involvement, as it encompasses an interactive relationship with the engagement object. Brodie et al. (2013) propose that the view of consumer engagement has theoretical roots within the expanded domain of relationship marketing and brand interactions. According to these authors, consumer engagement in a virtual brand community involves specific interactive experiences comprising positive cognitive and emotional dimensions, which are able to trigger behaviors (Hollebeek, Glynn and Brodie, 2014). In this sense, consumer engagement plays a central role in the process of relational exchange.

In the marketing literature, service-dominant logic was used to discuss engagement. The S-D logic defines customer engagement as a customer's motivationally driven, volitional investment of focal operant resources including cognitive, emotional, behavioral, social knowledge and skills, and operand resources (e.g. equipment) into brand interactions in service systems (Hollebeek et al., 2016). Consumer engagement 
can be passive, when the organization-related content is merely consumed, or active, when consumers contribute to or create organization-related content (Muntinga, Moorman, and Smit, 2011).

While consumer engagement has been shown to lead to sales growth, superior competitive advantage, and profitability (Bijmolt et al. 2010; Gambetti and Graffigna, 2010), it has not received the same attention from a stakeholder perspective. Greenwood (2007) defines stakeholder engagement as the practices an organization undertakes to involve stakeholders in a positive manner in its activities. Although stakeholder engagement often assumes that negotiations will be adversarial, more recent approaches interpret stakeholder engagement as a creative opportunity to engage in more collaborative and effective interactions (Corus and Ozanne, 2012).

Transferring the notion of consumer engagement (Brodie et al., 2013) to the stakeholder domain, this study examines the fluctuating intensity levels of engagement that occur among actors in the process of cocreating a mega-event. Engagement can be seen as a process that points to different levels and intensity of emotional, cognitive and behavioral activation (Gambetti and Graffigna, 2010). This study explores the emotional and cognitive components of engagement that trigger the behavioral activation component, in that this is a stage where engagement can effectively be measured through visible interactions. Extending the approach of passive and active customer engagement into the stakeholder perspective, this study differentiates between sources of mild engagement, i.e., compliant engagement, and sources of active engagement, i.e. interactive engagement (Van Doorn et al. 2010; Verleye et al. 2014). This multiple approach is consistent to the perceived prominence of the multidimensional perspective of engagement (Brodie et al., 2013).

As for consumer engagement, the diffusion of social media, and with it the increased use of interactive platforms such as blogs and user communities, has facilitated interactions among stakeholders as well as between stakeholders and organizations. On social media platforms stakeholders share information and experiences, discuss products/services and opinions, evaluate, and provide new product ideas or feedback (Viglia, 2014).

Within the stakeholder marketing literature, there is little empirical evidence substantiating how stakeholders engage in decision-making processes. More importantly, there is the need of evidence on how these processes take place online. Information Technology enables the combination of competences, capabilities, and knowledge (Srivastava \& Gnyawali, 2011). More specifically, social media can reflect real-world actions and practices that were started offline or they can actively represent a first initial pump priming for future real-world actions. These platforms are fruitful when stakeholders are interrelated as players, in that they can form a coalition for strengthening knowledge (Neville and Menguc, 2006) and more accurate decision-making (Invernizzi et al., 2017). The modality the information is made available is relevant. On the one hand social media extend networks by expanding the widespread and interrelations. On the other hand, to avoid energy and time dispersion and allow effective encounter moments, social media platforms might offer spaces with restricted access (closed groups).

\subsection{The constituents of stakeholder engagement}

Engagement has been defined in psychology by Kahn (1990) as the sum of supportive conditions for authentic expression. The identified fertile conditions for engagement according to this author can be grouped in two main areas, cognitive, such as a 
rational work goal, and emotional, i.e., a state of mind that affects behavior.

Following Doorn et al. (2010), customer engagement can be seen as customers' behavioral manifestations with a brand or firm, beyond purchase. Brodie et al.'s (2013) conceptual model on consumer engagement also reveals established relationships between the cognitive, emotional and behavioral aspects of consumer engagement. Such dimensions appear to be strategically important also for Hollebeek (2011), according to whom customer engagement is the level of a customer's motivational state of mind characterized by specific levels of cognitive and emotional activities during interactions with the brand or organization. Building on this reasoning and adopting a stakeholder approach the study portrays that:

\section{H1 Cognitive and emotional factors affect stakeholder engagement}

The emotional aspects that stem from feelings of gratitude, empathy and trust, are central for consumers engaging in the community (Brodie et al. 2013). This picture is rather different in the stakeholder territory where multi-stakeholders mainly engage with the focal organization because of goal-directed behaviors such as accomplishing some pre-determined purpose (Pera et al., 2016). In general, need for cognition is considered to be higher in stakeholders (Barnett, 2014) with respect to regular customers. Compared to consumers, multi-stakeholders are more functional and rational in their effort allocation, focusing on activities that are means to achieving an end.

H2a Cognitive factors are the strongest factor for interactive stakeholder engagement. Emotional factors will activate only compliant engagement

Social media enhances relationships among customers in business environments (Gamboa and Gonçalves, 2014).

In the stakeholder realm, the role of social platforms in enabling an active content generation is an under investigated issue. Ecosystem transformation occurs when stakeholders use and coordinate their resources (Letaifa et al., 2016) through a highly cognitive process. The increasing adoption of new ICTs, in particular social media, bolsters social interactions providing efficient ways of resource sharing and exchange highly valued content (Skålén et al., 2015). Thus, researchers should look at platforms with a social dimension to understand how change takes places, and how actors enable or inhibit resource transformation through active operant resources. Transformation is performed through an activation of a creative resource integration in terms of developing, combining, and changing other stakeholders' resources (i.e. the post) input in the system. This shift favors the engagement of an actor (e.g., stakeholder) from an individual role toward a goal-directed system. Given that ecosystem transformation is based on shared knowledge and sincere exchanges, the study proposes that:

$H 2 b$ The higher the cognitive level of depth of the shared content, the higher the level of engagement among stakeholders

\subsection{The actors involved in online stakeholder engagement}

The dynamic, and often real-time interaction boosted by social media has significantly changed the landscape for marketing management. One way to model 
the radical changes that social media introduce is the pinball metaphor (HennigThurau et al. 2010), which suggests that marketing in a social media environment resembles the chaotic and interactive game of pinball, having replaced the linear and one-directional bowling structured approach to marketing. Following such metaphor, there are two major differences that reflect the changes in marketing that have been associated with the rise of social media, (i) an increased active participation of stakeholders and (ii) a strong level of an ecosystem interconnectedness among different kinds of stakeholders. Such interconnectedness goes, indeed, beyond consumers, including different categories of stakeholders (employees, suppliers, competitors, etc.).

Stakeholders are becoming increasingly empowered, interconnected and willing to share their knowledge and ideas with firms and among themselves. In such stakeholder ecosystem control over marketing decisions is more dispersed. One of the broadest implications of the pinball metaphor is that companies have lost control of marketing activities because of stakeholders' empowerment and their interconnectedness. This many-to-many communication model sets the stage for a broad spectrum of expressive outlets that is taking over the top-down approach. As Pera et al. (2016) propose, digital communication encounters enable a multi-centred communication flow, where multi-stakeholders engage. This suggests a shift from a traditional top-down communication so typical of the goods-dominant logic, where the customer was simply considered a recipient of the stimulus sent by the communicating firm. A key challenge for marketing in these pinball times is to move from solo creators to cooperating moderators of the development of the social media content. The role of marketing managers changes from that of instigator to orchestrator of multiple stakeholder interactions (Gyrd-Jones \& Kornum, 2013). More formally,

H3 In multi-stakeholder online communities, pinball interactions among actors are more effective than top down induced activities from the focal organization

Figure 1 summarizes the conceptual framework, showing the interrelated mechanisms that lead to multi-stakeholder digital engagement (dotted lines represent weak relationships). The framework proposes how, within a multi-stakeholder ecosystem, stakeholders' digital engagement is the consequence of a cognitive activation rather than an emotional one. The latter is not sufficient per se to generate stakeholder interactive engagement. Additionally, the framework suggests that interactions among actors, rather than interactions led by the focal organization, are more powerful in harnessing stakeholder digital engagement.

\section{[INSERT FIGURE 1 HERE]}

\section{The empirical context}

Adopting a case study methodology (Yin, 2013), this work portrays a framework to understand the main characteristics of multi stakeholder digital engagement. The empirical setting for the study is the Universal Exhibition 2015 (Expo2015) hosted in Milan, Italy, between 1st May and 31st October 2015. Expo is a global event that is held every five years, aiming at "[...] educating the public, sharing innovation, promoting progress and fostering cooperation" [Internal document]. Participants included a variety of stakeholders involved in the global debate on the challenges related to food and nutrition. The Italian Government extended invitations to all 
United Nation state members, Non-Governmental Organizations (NGOs), and to local and global companies. Eventually, Expo2015 gathered 150 countries, attracting over 20 million visitors worldwide (Expo2015).

Within this setting, Expo2015 represented an opportunity for countries, NGOs, local and global food producers and other organizations to join the debate and showcase the latest innovations on nutrition and sustainability issues. This chosen context is appropriate for this study because of its dynamic collection of stakeholders that can be considered a service ecosystem (Vargo and Lusch, 2011). In this sense, interactions during this mega-event occur across a multiplicity of stakeholders. Specifically, interactions occur through self-adjusting and service-exchange relationships with over two hundred stakeholders. During the event relationships had both an offline and an online dimension. This paper focuses on the online perspective. To understand how multi-stakeholders engaged offline during the event, refer to Pera et al. (2016).

\section{Data}

The database collected consists of two types of dependent variables (likes and number of comments) and some input variables. The input variables are the type of information shared in the platform (photos, videos and links), some information on who wrote the post (an actor or the focal organization), the nature of the content (selfpromotion or more participative content), and the presence of transformation elements (i.e., in terms of activation of creative resource integration in posts). A set of control variables (gender, time of post, how many people saw the post) completes the available dataset.

Coherently with the conceptual model presented in Figure 1, visual variables (i.e., photos and videos) operationalize the emotional component while textual links operationalize the cognitive one. The data on the information on who wrote the post allow understanding the role of the focal organization while the nature of the content and the presence of transformation elements help to judge the level of depth of the relationships.

Data were collected between May and June 2016 in the Facebook page with restricted access for the 248 stakeholders involved in the event. With the goal of understanding the online dimension of compliant engagement and interactive engagement, our database consists of all the 984 posts published before, during and after Expo2015. In this sense, we collected the whole population of posts published in the closed Facebook page. The independent variables are dummy variables. The self-promotion variable and the transformation variable were collected on a 2-point scale $(0=a b s e n t$, $1=$ present ). A single coder was trained to code all the entries with respect to these

variables. To ensure the reliability of coding, another coder independently repeated the procedure on a 440 randomly chosen sub-sample as a reliability check, scoring $92 \%$ of similarity.

\section{Results}

The most relevant descriptive statistics of this final dataset are presented in Table 1. An average post received 7 likes and 4 comments among the members of the group. The standard deviation of these measures show a fairly high variability of likes and comments among posts. Photos are the most common shared material in posts, being present almost half of the times (46\%). A negligible amount of posts is written by the focal organization (10\%). The majority of posts are self-promotion with no transformation elements. As for the control variables, the average person who posted 
is female $(69.9 \%)$ and has posted more material during or after the event compared to what she has posted before. The average post has reached 216 people, which implies that was seen by $87 \%$ of the stakeholders involved in the Facebook page.

Social media tools typically measure different engagement levels based on the type of social interactions. Specifically, in the Facebook platform, likes, the number of comments and the type of shared material can be seen as a continuum of progressive levels of engagement (De Vries et al., 2012; Buhalis and Mamalakis, 2015; Mariani et al., 2016). Based on this literature, which also highlights how likes are just a form of compliance, we operationalize the mildest form of participation in the stakeholder Facebook page, compliance engagement, with the number of likes. On the contrary, interactive relationships require a higher order form of engagement and are more cognitive effortful (Rooderkerk and Pauwels, 2016). Stemming from this, two coders first analyzed semantically the content of the comments and then counted the ones that include a shared purpose (Skålén et al., 2015), coherently with the idea of interactive engagement. This analysis reduced the average number of comments with a shared purpose to 1.82 per post. This recoded variable was used as a proxy for collaboration.

\section{[INSERT TABLE 1 HERE]}

A regression analysis for each dependent variable measures the extent of the relationship between the independent variables and the analyzed construct. In order to decide which regression model is most appropriate, we assessed the extent of correlation between the independent variables with the aim to identify potential problems of multicollinearity. We adopted Spearman's rho correlation coefficient, a nonparametric measure of statistical dependence. The correlation between the variables is always well below the 0.7 threshold, suggesting no significant multicollinearity issues in this context. Accordingly, all the different determinants are regressed upon all the independent variables, with the inclusion of the interaction between focal organization and transformation elements, to capture if the benefit of transformative values holds when the portrayer is the focal organization (Expo2015). The regressions include also the impact of the identified control variables as Table 2 shows.

\section{[INSERT TABLE 2 HERE]}

Interestingly, while posts written by the focal organization trigger compliance, they have a negative effect on interactive engagement. Photos and videos, while stimulating passive compliant acts, have a detrimental effect on interactive engagement $(p<0.01)$. On the contrary, the analysis shows that the presence of links is useful for interactive engagement. Interestingly, the presence of transformation elements in the posts is a strong a predictor of both forms of engagement. The negative sign of the interaction between Focal organization and Transformation suggests a moderating effect. If the focal organization (Expo2015) activates transformative processes, this results in a negative effect on an interactive outcome. For what concerns the control variables, posts written by females seem to favor lower engagement while posts during and after the event generated more compliant behaviors. Finally, as expected, the more the post was seen, the more it generated cooperative and collaboration activities. The adjusted R-squared of all the presented 
models suggests a fairly good explanatory power of the models (around $50 \%$ of the variation of the engagement constructs).

In contrast with multiple regressions, which test the effects of individual independent variables on the outcome variable, qualitative comparative analysis (QCA) identifies combinations of causal conditions that can lead to the outcome of interest. This is of particular interest in this context, as in social media different conditions tend to generate different levels of engagement (Cvijikj and Michahelles, 2013; Sabate et al., 2014), but the recipe of these conjoint elements has not been investigated yet.

QCA performs a systematic cross-case analysis that models relations among variables in terms of set membership and identify configurations that reflect the necessary and sufficient conditions for an outcome of interest. To perform the analysis the first stage is identifying the property space, that is, the combinations of the 6 identified attributes that influence engagement levels (photos, videos, links, focal organization, selfpromotion, transformation). As some of the variables used are not dichotomous, the second step is using a fuzzy-set calibration approach to model the degrees to which different cases belong to a set, ranging from 0 to 1 , with intermediate membership levels (Ragin, 2000). By applying Boolean algebra rules (for a review, see Ordanini et al., 2014) it is then possible to build membership scores for configuration of attributes, which each of the attribute either present or absent.

The next stage is to identify which configurations of attributes can act as sufficient conditions for compliant and interactive behaviors. For a configuration to be considered sufficient, the consistency measure should exceed a minimum threshold of 0.75 (Woodside, 2014). In the fuzzy-set qualitative comparative analysis, the assessment of consistency represents the sum of the membership scores in the causal set that take to the expected outcome (i.e., different forms of engagement) divided by the sum of all the membership scores that pertain to that causal set. The final stage in applying QCA is to eliminate redundant attributes in the sufficient configurations. An attribute is redundant when its presence or absence is irrelevant for the outcome to be verified. For each reduced sufficient configuration, a coverage measure reflects the share of consistent membership as a portion of total membership in the outcome set. Table 3 presents the results from the QCA conducted by using the STATA fuzzy package (Longest and Vaisey, 2008).

\section{[INSERT TABLE 3 HERE]}

The rows clarify the configurations of attribute that are sufficient for inducing engagement behaviors, with consistency and coverage measures for each configuration and the whole solution. Five configurations that can all stimulate cooperative behaviors emerge. The 0.48 coverage solution stands out, that is, sharing a picture along with the absence of a link. Nonetheless, solutions are quite heterogeneous in this case, apart from focal organizational messages that play a positive role in all configurations. The interactive engagement output presents a completely different picture. One distinct configuration occurs. It consists of the presence of transformative elements and links, and the absence of photos, focal organization messages and self-presentation. Despite a low coverage for this solution due to a scarce presence of transformative elements (see Table 2) and the presence of 5 attributes that lowers the likelihood of this case, this solution presents an extremely high total consistency (0.94). As a post-hoc analysis, by running a sufficiency and necessity matrix, we found that the presence of transformation is the single element that is most sufficient for predicting the outcome (consistency $=0.76$ ). 
To assess the goodness of the QCA model, a fundamental issue regards the variable calibration into causal conditions and outcome. Although our calibration procedure was based on methodological guidelines in the QCA literature (Schneider and Wagemann 2010), and all the independent variables are dichotomous (0-1), we conducted additional checks to verify the robustness of our continuous outcomes across different calibration choices. Following Woodside (2012), we changed the threshold levels for the outcomes, originally being fuzzy score $=0.95$ for full membership, fuzzy score $=0.50$ for cross-over point and fuzzy score $=0.05$ for full non-membership. These three threshold values were set at $0.75,0.5$ and 0.25 . The results were the same as the ones presented in Table 3, suggesting that the findings are quite stable and robust.

In order to shed more insights, we also measured the no engagement outcome. In other words, we propose an additional analysis to explore the drivers of no compliant and no interactive behavioral engagements. Table 4 presents the causal conditions of no engagement. The absence of transformative elements is a consistent determinant of no engagement, both in its compliant and interactive forms. In terms of combinations of elements, the one with the highest coverage for no interactive engagement stands out (last row of Table 4). Specifically, this combination includes the absence of links and the presence of posts written by the focal organization. This result, which is consistent with the other combinations of no interactive engagement, gives complementary support to the findings from Table 3. Interestingly, self-promotion is associated to no interactive engagement in the final combination. However these results on no engagement should be taken with precaution as the general solution consistency of the model, 0.68 , is below the general accepted threshold levels (Greckhamer, 2013).

\section{[INSERT TABLE 4 HERE]}

\section{Discussion and conclusions}

The proposed study suggests that emotional activations such as photos and videos are not sufficient per se to generate stakeholder interactive engagement. Given the role of emotional activations just on the mildest form of engagement, i.e., compliant engagement, $\mathrm{H} 1$ is partially supported. One of the main findings of this research is the central role of cognition in stimulating stakeholders' active participation. This result, which strongly supports $\mathrm{H} 2 \mathrm{a}$, is in sharp contrast with the consumer literature on customer engagement (Brodie et al., 2013; Pera and Viglia, 2016). The level of analytical depth of the shared material, in terms of transformative content, appears of paramount importance to generate stakeholder interactive engagement. This finding is aligned with the theoretical knowledge on the desire to elaborate and share deep knowledge among actors ( $\mathrm{H} 2 \mathrm{~b})$. Interestingly, while the role of external focal organization in facilitating the connection among stakeholders is acknowledged, an active participation of tertius subjects (i.e., the focal organization) has a detrimental effect in terms of engagement, in line with $\mathrm{H} 3$.

The fsQCA analysis helps to expand the comprehension on the conditions needed for reaching each form of stakeholder engagement, compliant and interactive. The focal organization sharing of photos is sufficient to generate compliance as the weakest

form of engagement. However, for the highest source of engagement, i.e. stimulating comments with a shared purpose, much more is needed. In this domain, what stands 
out is the association between links, the most analytical source of sharing material, and transformative content in order to maximize interactive engagement. Studying the conditions for no engagement, results appear to be consistent, in that the absence of links and transformative content, along with messages posted by the focal organization, are clear conditions that leave interactive engagement away.

Despite the growing attention devoted to stakeholder marketing, mainstream marketing literature to date has not gone much further than observing that firms have multiple stakeholders (Hillebrand et al., 2015). This study addresses this call by defining the determinants of stakeholder engagement in digital environments.

Taking the debate beyond consumer engagement, this study confirms that social media have changed the marketing game. The data show how the focal organization's role in harnessing stakeholder engagement is not straightforward. While it is able to boost compliant engagement, it is not able to produce interactive engagement, highlighting a lack of control of the process. Stakeholder interactive engagement requires functional and rational shared content and it is enhanced when there is complementarity across stakeholders. The control over the digital marketing activities, which used to be centralized in the organization, is becoming dispersed across stakeholders. As for what happens in the studies that focus on consumer engagement, this analysis confirms that the marketing world needs to move from bowling to pinball. This view supports the original nature of social media as a consumer-to-consumer interaction and alerts brand and organizations about the effective usage of social media content.

While for harnessing offline stakeholder engagement fundamental enablers are regular interactions, non-hierarchical dialogue and direct and open communication (Pera et al. 2016), the implications for online stakeholder engagement appear more complex. When the focal organization activates transformative processes, this results in a negative effect. Contrarily, the focal organization should be effective in identifying and interacting with the key stakeholders who, thanks to their resources and their social narrative abilities, are able to create a vision and engage other stakeholders, becoming the true ambassadors.

Our conclusions are limited to the context of the study. Further research might be based on analyzing more traditional environments, such as commercial brands, and other type of stakeholders including suppliers. In an event featured by time limitations and a joint place, such as the case of the Expo, and other events such as music festivals, trade fairs, or tourism events, it might be of interest to evaluate the interplay between the online and offline dimension. The analysis of this dual and bidirectional (online $\rightarrow$ offline, and offline $\rightarrow$ online) effect may contribute to a better understanding of stakeholder engagement.

Finally, future research could determine the impact of the content shared within the Facebook closed group on the broader digital ecosystem. By adopting a network analysis of such broader digital ecosystem, research could unveil which and how multi-stakeholders transform contents beyond restricted endeavors. 


\section{References}

Barnett, M. L. (2014). Why stakeholders ignore firm misconduct: A cognitive view. Journal of Management, 40(3), 676-702.

Barrena, J., López, M., \& Romero, P. M. (2016). Corporate social responsibility: Evolution through institutional and stakeholder perspectives. European Journal of Management and Business Economics, 25(1), 8-14.

Bijmolt, T. H. A., Leeflang, P. S. H., Block, F., Eisenbeiss, M., Hardie, B. G. S., Lemmens, A., \& Saffert, P. (2010). Analytics for customer engagement. Journal of Service Research, 13(3), 341-356.

Brodie, R. J., Ilic, A., Juric, B., \& Hollebeek, L. (2013). Consumer engagement in a virtual brand community: An exploratory analysis. Journal of Business

Research, 66(1), 105-114.

Buhalis, D., \& Mamalakis, E. (2015). Social media return on investment and performance evaluation in the hotel industry context. In Information and Communication Technologies in Tourism 2015 (pp. 241-253). Springer International Publishing.

Choi, J., \& Wang, H. (2009). Stakeholder relations and the persistence of corporate financial performance. Strategic Management Journal, 30, 895-907.

Corus, C., \& Ozanne, J. L. (2012). Stakeholder engagement: Building participatory and deliberative spaces in subsistence markets. Journal of Business Research, 65(12), 1728-1735.

Cvijikj, I. P., \& Michahelles, F. (2013). Online engagement factors on Facebook brand pages. Social Network Analysis and Mining, 3(4), 843-861.

De Vries, L., Gensler, S., \& Leeflang, P. S. (2012). Popularity of brand posts on brand fan pages: An investigation of the effects of social media marketing. Journal of Interactive Marketing, 26(2), 83-91.

Dijkmans, C., Kerkhof, P., \& Beukeboom, C. J. (2015). A stage to engage: Social media use and corporate reputation. Tourism Management, 47, 58-67.

Driessen, P. H., Kok, R. A. W., \& Hillebrand, B. (2013). Mechanisms for Stakeholder Integration: Bringing Virtual Stakeholder Dialogue into Organizations. Journal of Business Research, 66(9), 1465-1472.

Gambetti, R., \& Graffigna, G. (2010). The concept of engagement. International Journal of Market Research, 52(6), 801-826. 
Gamboa, A. M., \& Gonçalves, H. M. (2014). Customer loyalty through social networks: Lessons from Zara on Facebook. Business Horizons, 57(6), 709-717.

Gyrd-Jones, R. I., \& Kornum, N. (2013).Managing the co-created brand: Value and cultural complementarity in online and offline multi-stakeholder ecosystems. Journal of Business Research, 66(9), 1484-1493.

Greckhamer, T., Misangyi, V. F., \& Fiss, P. C. (2013). Chapter 3 The Two QCAs: From a Small-N to a Large-N Set Theoretic Approach. In Configurational theory and methods in organizational research (pp. 49-75). Emerald Group Publishing Limited.

Greenwood, M. (2007). Stakeholder Engagement: Beyond the Myth of Corporate Responsibility. Journal of Business Ethics, 74(4): 315-327.

Hennig-Thurau, Thorsten, Edward C. Malthouse, Christian Friege, Sonja Gensler, Lara Lobschat, Arvind Rangaswamy, and Bernd Skiera (2010). The Impact of New Media on Customer Relationships. Journal of Service Research, 13(3), 311-30.

Hennig-Thurau, T., Hofacker, C. F., \& Bloching, B. (2013). Marketing the pinball way: understanding how social media change the generation of value for consumers and companies. Journal of Interactive Marketing, 27(4), 237-241.

Hillebrand, B., Driessen, P. H., \& Koll, O. (2015). Stakeholder marketing: theoretical foundations and required capabilities. Journal of the Academy of Marketing Science, $1-18$.

Hollebeek, L. D., Srivastava, R. K., \& Chen, T. (2016). SD logic-informed customer engagement: integrative framework, revised fundamental propositions, and application to CRM. Journal of the Academy of Marketing Science, 1-25.

Invernizzi, A. C., Menozzi, A., Passarani, D. A., Patton, D., \& Viglia, G. (2017). Entrepreneurial overconfidence and its impact upon performance. International Small Business Journal, 35(6), 709-728.

Kahn, W. A. (1990). Psychological conditions of personal engagement and disengagement at work. Academy of management journal, 33(4), 692-724.

Letaifa, S. B., Edvardsson, B., \& Tronvoll, B. (2016). The role of social platforms in transforming service ecosystems. Journal of Business Research, 69(5), 1933-1938.

Longest, K. C., \& Vaisey, S. (2008). Fuzzy: A program for performing qualitative comparative analyses (QCA) in Stata. Stata Journal, 8(1), 79.

Maignan, I., \& Ferrell, O. C. (2004). Corporate social responsibility and marketing: an integrative framework. Journal of the Academy of Marketing Science, 32, 3-19.

Mariani, M. M., Di Felice, M., \& Mura, M. (2016). Facebook as a destination marketing tool: Evidence from Italian regional Destination Management Organizations. Tourism Management, 54, 321-343. 
Martí, J., Bigné, E. \& Hyder, A. (2014). Brand engagement, in Bigné, E. and Manrai, A.K. (eds.) (2014). The Routledge Companion on the Future of Marketing, Routledge, London, pp. 250-267.

Merz, M. A., He, Y., \& Vargo, S. L. (2009). The evolving brand logic: a servicedominant logic perspective. Journal of the Academy of Marketing Science, 37(3), 328-344.

Mollen, A., \& Wilson, H. (2010). Engagement, telepresence and interactivity in online consumer experience: Reconciling scholastic and managerial perspectives. Journal of business research, 63(9), 919-925.

MSI - Marketing Science Institute (2014). Research priorities 2014-2016. Retrieved November 7, 2016 from: http://www.msi.org/uploads/files/MSI_RP14-16.pdf.

MSI -Marketing Science Institute (2016). Research priorities 2016-2018. Retrieved July 15, 2016 from: http://www.msi.org/research/2016-

2018-research-priorities/.

Muntinga, D. G., Moorman, M., \& Smit, E. G. (2011). Introducing COBRAs: Exploring motivations for brand-related social media use. International Journal of advertising, 30(1), 13-46.

Neville, B. A., \& Menguc, B. (2006). Stakeholder multiplicity: Toward an understanding of the interactions between stakeholders. Journal of Business Ethics, 66(4), 377-391.

Ordanini, A., Parasuraman, A., \& Rubera, G. (2013). When the recipe is more important than the ingredients a qualitative comparative analysis (QCA) of service innovation configurations. Journal of Service Research, 17(2), 134-149.

Pera, R., Occhiocupo, N., \& Clarke, J. (2016). Motives and resources for value cocreation in a multi-stakeholder ecosystem: A managerial perspective. Journal of Business Research, 69(10), 4033-4041.

Pera, R., \& Viglia, G. (2016). Exploring how video digital storytelling builds relationship experiences. Psychology \& Marketing, 33(12), 1142-1150.

Rooderkerk, R. P., \& Pauwels, K. H. (2016). No comment?! The drivers of reactions to online posts in professional groups. Journal of Interactive Marketing, 35, 1-15.

Sabate, F., Berbegal-Mirabent, J., Cañabate, A., \& Lebherz, P. R. (2014). Factors influencing popularity of branded content in Facebook fan pages. European Management Journal, 32(6), 1001-1011.

Schmitt, B. (2012). The consumer psychology of brands. Journal of Consumer Psychology, 22(1), 7-17. 
Schneider, C. Q., \& Wagemann, C. (2010). Standards of good practice in qualitative comparative analysis (QCA) and fuzzy-sets. Comparative Sociology, 9(3), 397-418.

Skålén, P., Pace, S., \& Cova, B. (2015). Firm-brand community value co-creation as alignment of practices. European Journal of Marketing, 49(3/4), 596-620.

Srivastava, M. K., \& Gnyawali, D. R. (2011). When do relational resources matter? Leveraging portfolio technological resources for breakthrough innovation. Academy of Management Journal, 54(4), 797-810.

Surroca, J., Tribó, J. A., \& Waddock, S. (2010). Corporate responsibility and financial performance: the role of intangible resources. Strategic Management Journal, 31, $463-490$.

Vargo, S. L. (2011). Market systems, stakeholders and value propositions. Toward a service-dominant logic-based theory of the market. European Journal of Marketing, 45(1/2), 217-222.

Van Doorn, J., Lemon, K. N., Mittal, V., Nass, S., Pick, D., Pirner, P., \& Verhoef, P. C. (2010). Customer engagement behavior: Theoretical foundations and research directions. Journal of Service Research, 13(3), 253-266.

Verleye, K., Gemmel, P., \&Rangarajan, D. (2014). Managing engagement behaviors in a network of customers and stakeholders: Evidence from the nursing home sector. Journal of Service Research, 17(1), 68-84.

Viglia, G. (2014). Pricing, Online Marketing Behavior, and Analytics. Springer.

Woodside, A. G. (2012). Proposing a new logic for data analysis in marketing and consumer behavior: Case study research of large-N survey data for estimating algorithms that accurately profile X (extremely high-use) consumers. Journal of Global Scholars of Marketing Science, 22(4), 277-289.

Woodside, A. G. (2014). Embrace• perform• model: Complexity theory, contrarian case analysis, and multiple realities. Journal of Business Research, 67(12), 24952503.

Yin, R. K. (2013). Case study research: Design and methods. Thousand Oaks, CA: Sage publications. 
List of Tables and Figures

\section{Table 1. Descriptive statistics $(n=984)$}

\begin{tabular}{llcl} 
Type of variable & Variable & Average & SD \\
\hline Dependent & Number of likes & 6.87 & 5.61 \\
variables & Number of comments & 4.12 & 2.69 \\
\hline Independent & Post with photo (0: no; 1: yes) & 453 & \\
variables & Post with video (0: no; 1: yes) & 59 & \\
& Post with links (0:no; - 1: yes) & 226 & \\
& Focal organization (0: actor; 1 if the post & 98 & \\
& was written by the focal organization) & & \\
& Self-promotion (0: no; - 1: yes) & 846 & \\
& Transformation elements (0: no - 1: yes) & 30 & \\
\hline Control variables & Gender (1 female) & 679 & \\
& Time of post (-1; 0; 1) & 0.01 & \\
& Seen by & 215.78 & 29.71 \\
\hline
\end{tabular}

Time of post is a discrete variable that categorizes if the post was written before the event $(=-$ $1)$, during the event $(=0)$ or after the event $(=1)$. Seen by is a quantitative measure used to indicate how many members of the community have seen the post. 
Table 2. Determinants of compliant engagement (CE) and interactive engagement (IE)

Dependent Variable CE IE

\begin{tabular}{lll}
\hline Photos & $2.741^{* * *}$ & $-0.922^{* * *}$ \\
Videos & $(0.448)$ & $(0.217)$ \\
& $1.458^{*}$ & $-1.162^{* * *}$ \\
Links & $(0.744)$ & $(0.360)$ \\
& 0.0128 & $1.598^{* * *}$ \\
Focal organization & $(0.501)$ & $(0.242)$ \\
& $5.935^{* * *}$ & $-1.579^{* * *}$ \\
Self-promotion & $(0.580)$ & $(0.281)$ \\
& 0.548 & -0.125 \\
Transformation & $(0.427)$ & $(0.207)$ \\
& $2.859^{* *}$ & $1.335^{*}$ \\
Focal*Transform & $(1.455)$ & $(0.704)$ \\
& 1.795 & $-4.111^{* * *}$ \\
Gender & $(1.972)$ & $(0.955)$ \\
Time of post & $-0.795^{* *}$ & $-0.298^{*}$ \\
& $(0.358)$ & $(0.174)$ \\
Seen by & $6.260^{* * *}$ & 0.0662 \\
& $(0.929)$ & $(0.450)$ \\
\hline Constant & $0.0268^{* * *}$ & $0.0146^{* * *}$ \\
& $(0.00592)$ & $(0.00286)$ \\
\hline Observations & -0.907 & -0.447 \\
Adjusted R-squared & $(1.354)$ & $(0.656)$ \\
\hline
\end{tabular}

$* * * p<0.01, * * p<0.05, * p<0.1$

Note: Robust standard errors in parentheses

Table 3. Sufficient configurations for compliant engagement (CE) and interactive engagement (IE)

\begin{tabular}{lllll} 
Output & Sufficient Sets & Raw Coverage & $\begin{array}{l}\text { Unique } \\
\text { Coverage }\end{array}$ & $\begin{array}{l}\text { Solution } \\
\text { Consistency }\end{array}$ \\
\hline & & & 0.01 & 0.98 \\
& $\mathrm{p}^{*} \mathrm{I}^{*} \mathrm{~F}^{*} \mathrm{~s} \mathrm{~T}^{*} \mathrm{~T}$ & 0.01 & 0.01 & 0.90 \\
$\mathrm{CE}$ & $\mathrm{p} \mathrm{L}^{*} \mathrm{~F}^{*} \mathrm{~s}$ T & 0.03 & 0.01 & 0.94
\end{tabular}




\begin{tabular}{lllll} 
& $\mathrm{P} * \mathrm{l} * \mathrm{~F}$ & 0.51 & 0.48 & 0.76 \\
& $\mathrm{p} * \mathrm{~F}^{*} \mathrm{~S} \mathrm{t}_{\mathrm{t}}$ & 0.03 & 0.02 & 0.91 \\
\hline $\mathrm{IE}$ & $\mathrm{p} \mathrm{L}^{*} \mathrm{f} * \mathrm{~s} * \mathrm{~T}$ & 0.02 & 0.02 & 0.94 \\
\hline
\end{tabular}

Note: $P=$ photos, $L=$ links, $F=$ focal organization, $S=$ self-promotion, $T=$ transformation Lowercase $=$ attribute absent, uppercase $=$ attribute present

Total coverage $=0.57$. Solution consistency $=0.80$ for the compliant engagement model .

Table 4. Sufficient configurations for no compliant engagement (no CE) and no interactive engagement (no IE)

\begin{tabular}{|c|c|c|c|c|}
\hline Output & Sufficient Sets & Raw Coverage & $\begin{array}{l}\text { Unique } \\
\text { Coverage }\end{array}$ & $\begin{array}{l}\text { Solution } \\
\text { Consistency }\end{array}$ \\
\hline \multirow[t]{2}{*}{ no $\mathrm{CE}$} & $\mathrm{p}^{*} \mathrm{v} * \mathrm{f} * \mathrm{~s} * \mathrm{t}$ & 0.41 & 0.25 & 0.82 \\
\hline & $\mathrm{p}^{*} \mathrm{v}^{*} \mathrm{~L} * \mathrm{f} * \mathrm{t}$ & 0.23 & 0.07 & 0.59 \\
\hline \multirow{3}{*}{ no IE } & $\mathrm{p}^{*} \mathrm{v}^{*} \mathrm{l}^{*} \mathrm{~F} * \mathrm{t}$ & 0.23 & 0.23 & 0.73 \\
\hline & $\mathrm{p} * \mathrm{~V} * 1 * \mathrm{~F} * \mathrm{t}$ & 0.05 & 0.05 & 0.63 \\
\hline & $\mathrm{P}^{*} \mathrm{v}^{*} \mathrm{l}^{*} \mathrm{~F}^{* \mathrm{t}}$ & 0.45 & 0.45 & 0.67 \\
\hline
\end{tabular}

Note: $P=$ photos, $V=$ videos, $L=$ links, $F=$ focal organization, $S=$ self-promotion, $T=$ transformation

Lowercase $=$ attribute absent, uppercase $=$ attribute present

Total coverage $=0.47$. Solution consistency $=0.68$ for the compliant engagement model

Total coverage $=0.73$. Solution consistency $=0.68$ for the interactive engagement model

\section{Figure 1: Conceptual framework}

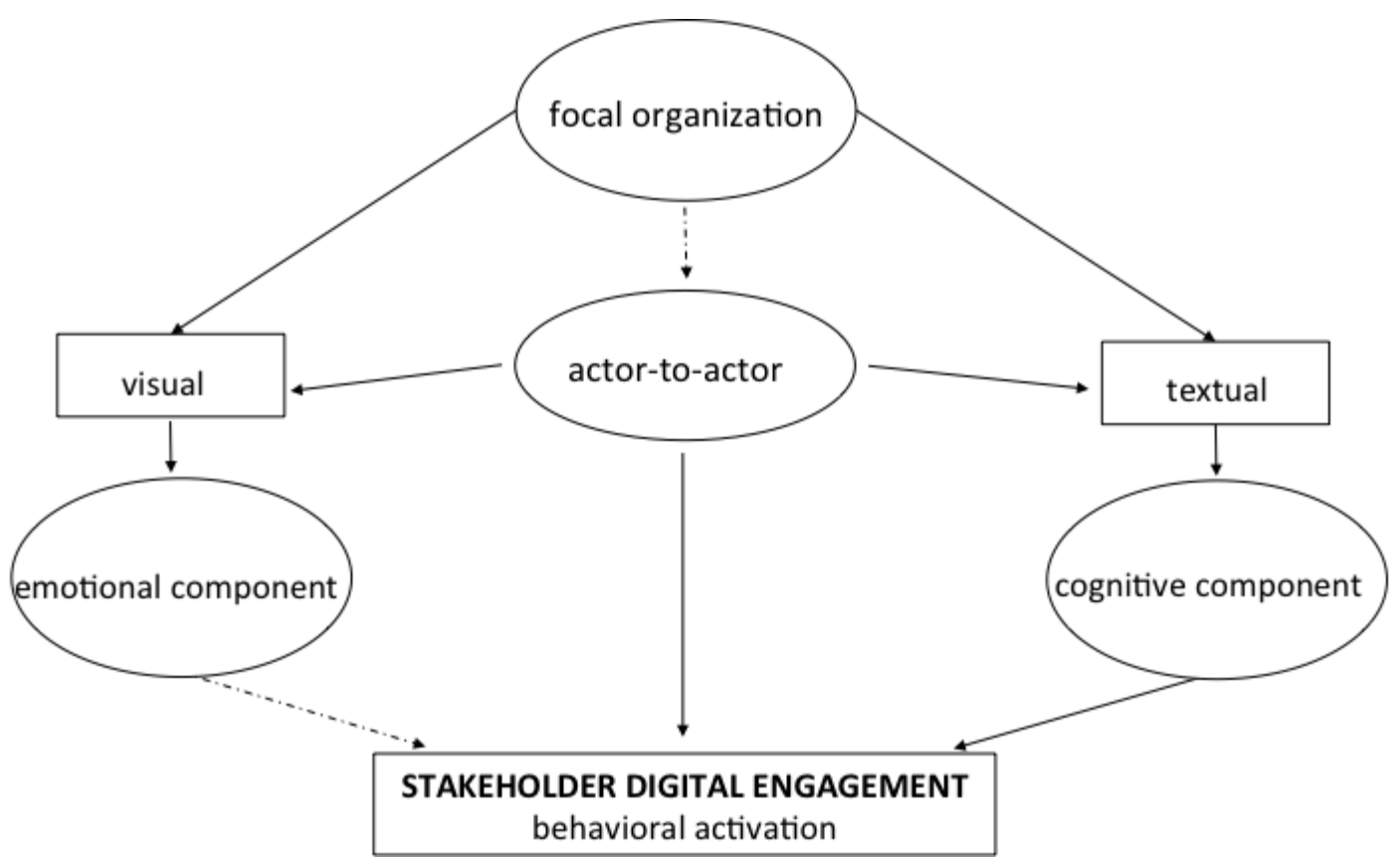

